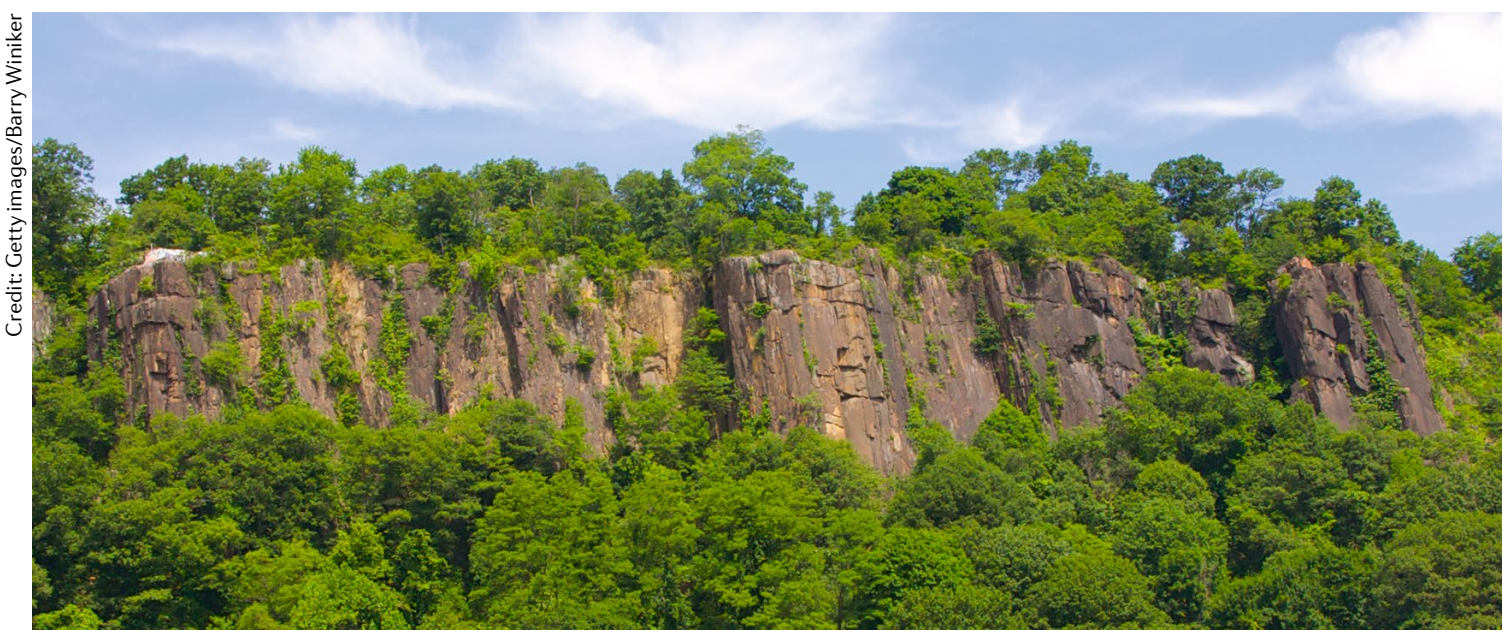

LARGE IGNEOUS PROVINCES

\title{
End-Triassic carbon runs deep
}

Large igneous provinces (LIPs) are formed through the rapid emplacement of millions of $\mathrm{km}^{3}$ of magma over geologically short timescales, $<1$ million years. Owing to their coincidence with many mass extinctions, gases such as $\mathrm{CO}_{2}$ released during LIP emplacement are thought to have triggered catastrophic climate changes. The Central Atlantic Magmatic Province (CAMP), for example, is linked to the end-Triassic mass extinction, one of the 'Big Five'. However, the volume and relative contributions of sedimentary, crustal and mantle $\mathrm{CO}_{2}$ released by CAMP are unconstrained.

Manfredo Capriolo, from the University of Padova, Italy, and colleagues analysed $\mathrm{CO}_{2}$ trapped in melt inclusions of CAMP basaltic rocks using a combination of petrographic, spectroscopic and geochemical approaches. $\mathrm{CO}_{2}$ concentrations up to $1 \mathrm{wt} \%$ were identified for CAMP magmas and application of petrological barometers reveal that this $\mathrm{CO}_{2}$ is likely derived from the mantle and/or the mid-crust to lower-crust. Such high concentrations of $\mathrm{CO}_{2}$ indicate that up to $10^{5}$ gigatons of $\mathrm{CO}_{2}$ may have been released during CAMP emplacement. This $\mathrm{CO}_{2}$ could have acted as a propellant for the rising magma, explaining why the periodic CAMP eruptions were fast and left little time for the environment to adjust to the increased atmospheric $\mathrm{CO}_{2}$ concentrations. For example, one magmatic episode of only 500 years could have emitted a volume of $\mathrm{CO}_{2}$ equivalent to that projected to be emitted during the $21^{\text {st }}$ century, assuming a $2{ }^{\circ} \mathrm{C}$ climate warming scenario. This finding suggests parallels between the endTriassic mass extinction and the near-future impacts of anthropogenic climate change.

Though the impact of CAMPrelated $\mathrm{CO}_{2}$ emissions on the Triassic climate and biosphere were not modelled here, the estimates lend further evidence to the role of CAMP in one of the great mass extinctions. Continued research into connections between volcanic degassing, climate and biosphere responses not only reveals Earth's history, but offers insights into the sixth mass extinction as Earth heats up.

Laura Zinke

ORIGINAL ARTICLE Capriolo, M. et al. Deep $\mathrm{CO}_{2}$ in the end-Triassic Central Atlantic Magmatic Province. Nature Communications 11, $1670(2020)$ 